\title{
Inebriated liver causing mesangial turmoil
}

\begin{abstract}
IgA nephropathy is the most common primary glomerular disease worldwide, diagnosed $10 \%$ of renal biopsies in the United States, up to $20 \%$ in Europe and approximately $40 \%$ in Asia, the latter being the leading cause of ESRD in Asia. Multiple studies have shown the relationship between cirrhosis and the development of glomerular lesions leading IgA deposition in the mesangium causing IgAN. Here we present an unusual case of a 64-yearold female presenting with IgA nephropathy induced by liver cirrhosis.
\end{abstract}

Keywords: glomerular lesions, IgA nephropathy, hepatocellular carcinoma
Volume II Issue I - 202I

Luis Caraballo,' Adalberto Gonzalez,2 Joel

Brooks, ${ }^{2}$ Evelyn Bryon, ${ }^{2}$ Jose G Pantaleon,2 Jose Gascon ${ }^{2}$

'Department of internal medicine, Kendall Regional medical center, USA

${ }^{2}$ Department of Gastroenterology, Cleveland Clinic Florida, USA

Correspondence: Luis Caraballo, Department of internal medicine, Kendall Regional medical center, USA,

Email Icaraballo86@gmail.com

Received: December 15, 2020 | Published: January 12, 202 1

\section{Case presentation}

A 64-year-old female presented to the emergency department(ED) after a one week history of unexplained rash in the lower extremities. The rash began as a red, non palpable lesion located in the ankles bilaterally, that later on progressed to a purple lesion extending towards the mid portion of both thighs. Rash was associated with fatigue, generalized sharp abdominal pain, $3 / 10$ in intensity that progressed to $7 / 10$ in the last 3 days, also reported abdominal distention with non-exertional shortness of breath. The past medical history was significant for Hepatocellular carcinoma, alcohol induced cirrhosis undergoing liver transplant evaluation. On evaluation vital signs: Blood pressure 100/56mmhg, Heart rate 126, Respiratory rate 16 , saturating $97 \%$ on room air. Physical exam was significant for purple macular, non-tender rash located in the ankles, extending to the mid-portion of the inner thigh bilaterally and hypogastric area, and non-tender abdominal distention with dry mucous membranes. The initial laboratory evaluation at the hospital revealed an elevated creatinine level at 2.39, a BUN of 22, total bilirubin 1.9 and INR 1.5, with normal transaminase, decreased complement $\mathrm{C} 3, \mathrm{C} 4$ levels at 51 and 11 respectively. Abdominal ultrasound done in the ED reported moderate ascites, therapeutic paracenthesis was done significantly improving abdominal distention. Albumin was administered no improvement of renal function. Skin biopsy was performed and reported early lesion of leukocytoclastic vasculitis. Due to high suspicion of Henoch-Schonlein Purpura, 60mg of prednisone was started and significant improvement of renal function was noted. Renal biopsy showed deposition of $\operatorname{IgA}$ in the glomerulus confirming the etiology suspected. ${ }^{1-8}$

\section{Discussion}

Glomerular deposits of IgA have been reported in 35\% to $90 \%$ on cirrhotic patients. It has been previously stated that the majority of IgA synthesis in humans is mucosal, polymeric IgA with two isotypes, IgA1 and IgA2. Limited polymeric IgA reaches to human mucosal. Polymeric IgA2 is mainly eliminated through the hepatic asialoglycoprotein receptor as compared to Polymeric IgA1, this explains the reason why a higher percentage of polymeric IgA2 has been noted in the circulation of patients with chronic liver disease. ${ }^{9}$
Liver cirrhosis has been associated with the development of IgA nephropathy, pathogenesis remains uncertain, but is thought that inadequate liver IgA circulating immune complex metabolism leads to tissue deposition, and subsequently developing $\operatorname{IgA}$ nephritis. Nonetheless, It hasn't been established the degree of liver involvement associated with deposition of IgA immune complexes. ${ }^{10}$ In the present case, after confirming the etiology with skin and renal biopsy $\operatorname{Ig} \mathrm{A}$ nephropathy was diagnosed and was suspected to be associated with liver cirrhosis. Our approach with prednisone $60 \mathrm{mg}$ showed significant improvement of renal function after the first week of treatment.

\section{Conflicts of interest}

The author declares no conflicts of interest.

\section{Acknowledgments}

None.

\section{Funding}

None.

\section{References}

1. Rodrigues JC, Haas M, Reich HN. IgA Nephropathy. Clin J Am Soc Nephrol. 2017;12(4):677-686.

2. Jennette JC, Falk RJ, Bacon PA, et al. 2012 revised International Chapel Hill Consensus Conference Nomenclature of Vasculitides. Arthritis Rheum. 2013;65(1):1-11.

3. Nickavar, Azar. Treatment of Henoch schonlein nephritis; new trends. Journal of nephropathology. 2016;5(4):116-117.

4. Aggarwal Manju, Connie L Mansk, Peter JL et al. Henoch-Schönlein vasculitis as a manifestation of $\mathrm{IgA}$-associated disease in cirrhosis. American journal of kidney diseases. 1992;20(4):400-402.

5. Nielsen HE: Epidemiology of Schonlein-Henoch purpura. Acta Paediatr Scand. 1988;77(1):125-131.

6. Pillebout, Evangéline, et al. Henoch-Schönlein purpura in adults: outcome and prognostic factors. Journal of the American Society of Nephrology. 2002;13(5):1271-1278. 
7. Galla HJ, IgA nephropathy. Kidney international. 1995;47(2):377-387.

8. Rifai A, Fadden K, Morrison SL, et al. The N-glycans determine the differential blood clearance and hepatic uptake of human immunoglobulin (Ig)A1 and IgA2 isotypes. J Exp Med. 2000;191(12):2171-2182.

9. Delacroix DL, Elkom KB, Geubel AP, et al. Changes in size, subclass, and metabolic properties of serum immunoglobulin $\mathrm{A}$ in liver diseases and in other diseases with high serum immunoglobulin A. J Clin Invest. $1983 ; 71(2): 358-367$.
10. Kalambokis Georgios, Leonidas Christou, Dimitrios Stefanou, et al. Association of liver cirrhosis related $\operatorname{IgA}$ nephropathy with portal hypertension. World Journal of Gastroenterology: WJG. 2007;13(43):5783-5786.

11. Madison DL, E Allen A, Deodharet al. Henoch-Schönlein purpura: a possible complication of hepatitis Crelated liver cirrhosis. Annals of the rheumatic diseases. 2002;61(3):281-282. 